Marquette University

e-Publications@Marquette

Biomedical Engineering Faculty Research and

Publications

Biomedical Engineering, Department of

$4-2013$

\title{
Brief Report: Visuo-spatial Guidance of Movement during Gesture Imitation and Mirror Drawing in Children with Autism Spectrum Disorders
}

\author{
Nicole M.G. Salowitz \\ Marquette University \\ Petra Eccarius \\ Indiana University - Purdue University Indianapolis \\ Audrey Meyer Carson \\ Marquette University \\ Kirsten A. Schohl \\ Marquette University \\ Sheryl Jayne Stevens \\ Marquette University
}

See next page for additional authors

Follow this and additional works at: https://epublications.marquette.edu/bioengin_fac

Part of the Biomedical Engineering and Bioengineering Commons

\section{Recommended Citation}

Salowitz, Nicole M.G.; Eccarius, Petra; Carson, Audrey Meyer; Schohl, Kirsten A.; Stevens, Sheryl Jayne; Vaughan van Hecke, Amy; and Scheidt, Robert A., "Brief Report: Visuo-spatial Guidance of Movement during Gesture Imitation and Mirror Drawing in Children with Autism Spectrum Disorders" (2013).

Biomedical Engineering Faculty Research and Publications. 160.

https://epublications.marquette.edu/bioengin_fac/160 


\section{Authors}

Nicole M.G. Salowitz, Petra Eccarius, Audrey Meyer Carson, Kirsten A. Schohl, Sheryl Jayne Stevens, Amy Vaughan van Hecke, and Robert A. Scheidt 
Marquette University

\section{e-Publications@Marquette}

\section{Biomedical Engineering Faculty Research and Publications/College of Arts and Sciences}

This paper is NOT THE PUBLISHED VERSION; but the author's final, peer-reviewed manuscript. The published version may be accessed by following the link in the citation below.

Journal of Autism and Developmental Disorder, Vol. 43, No. 4 (April 2013): 985-995. DOI. This article is (C) Springer and permission has been granted for this version to appear in e-Publications@Marquette. Springer does not grant permission for this article to be further copied/distributed or hosted elsewhere without the express permission from Springer.

\section{Brief Report: Visuo-spatial Guidance of Movement during Gesture Imitation and Mirror Drawing in Children with Autism Spectrum Disorders}

Nicole M. G. Salowitz

Department of Biomedical Engineering, Olin Engineering Center, Marquette University, Milwaukee, USA

Petra Eccarius

Department of Radiology, Indiana University School of Medicine, Indianapolis, USA

Jeffrey Karst

Department of Psychology, Marquette University, Milwaukee, USA

Audrey Carson

Department of Psychology, Marquette University, Milwaukee, USA

Kirsten Schohl

Department of Psychology, Marquette University, Milwaukee, USA 


\title{
Sheryl Stevens
}

Department of Psychology, Marquette University, Milwaukee, USA

\author{
Amy Vaughan Van Hecke \\ Department of Psychology, Marquette University, Milwaukee, USA
}

\section{Robert A. Scheidt}

Department of Biomedical Engineering, Olin Engineering Center, Marquette University, Milwaukee, USA Physical Medicine and Rehabilitation, Feinberg School of Medicine, Northwestern University, Chicago, USA Neurology, Medical College of Wisconsin, Milwaukee, USA

\section{Abstract}

Thirteen autistic and 14 typically developing children (controls) imitated hand/arm gestures and performed mirror drawing; both tasks assessed ability to reorganize the relationship between spatial goals and the motor commands needed to acquire them. During imitation, children with autism were less accurate than controls in replicating hand shape, hand orientation, and number of constituent limb movements. During shape tracing, children with autism performed accurately with direct visual feedback, but when viewing their hand in a mirror, some children with autism generated fewer errors than controls whereas others performed much worse. Large mirror drawing errors correlated with hand orientation and hand shape errors in imitation, suggesting that visuospatial information processing deficits may contribute importantly to functional motor coordination deficits in autism.

\section{Keywords}

Motor control, Sensorimotor transformation, Coordination, Visuospatial information processing, Goal-directed movement

\section{Introduction}

Most people easily modify hand movements to compensate for computer mousing errors caused by holding the mouse at an angle. Compensation depends on the brain's ability to adjust the relationship or "mapping" between an intended movement and the motor commands (muscle activities, joint torques) needed to perform it. Most actions are sensorimotor in nature in that ongoing task performance is adjusted using sensory information to shape the motor commands needed to compensate for deviations from the intended action. In this way, behavior depends on the integrity of neural mechanisms that process sensory information, those that process motor information and those that bridge the two information sources to generate coordinated action. Children with autism often exhibit clumsiness (Ghaziuddin and Butler 1998) as well as abnormalities in sensory information processing (American Psychiatric Association 1994; Lane et al. 2010; O’Neill and Jones 1997; Wiggins et al. 2009). While there is conflicting evidence supporting a general coordination deficit in autism (Ghaziuddin et al. 1994; Rinehart et al. 2001, 2006; Gidley Larson et al. 2008; Mostofsky et al. 2004), people with autism often exhibit specific motor impairments related to movement planning (Rinehart et al. 2001, 2006; Glazebrook et al. 2008; Schmitz et al. 2003), task sequencing (Hill 2004) and postural control (Molloy et al. 2003; Minshew et al. 2004). We hypothesize that sensory and motor deficits are causally linked in this population, i.e. that abnormal sensory information processing is a direct cause of quantifiable motor coordination deficits.

We used gesture imitation and mirror drawing tasks to compare how autistic and typically developing children transform visuospatial goals into arm and hand motions. Imitation is a real-life behavior important for social interaction and the development of language skills (lacoboni 2005)-two domains that show impairment in autism (American Psychiatric Association 1994; Hermelin and O'Connor 1970). Imitation requires participants to 
direct visual attention to relevant aspects of a demonstrated movement (i.e. "encoding" see Vivanti et al. 2008), to commit the demonstrated movements and the visuospatial goals they represent to working memory and then to transform such representations into action. It is known that the ability to imitate is impaired in children (Rogers et al. 2003; Stone et al. 1997; Haswell et al. 2009; Ohta 1987; Bernabei et al. 2003) and adults (Leighton et al. 2008) with autism (for review see Williams et al. 2001). Because deferred imitation tasks have yielded conflicting results (Rogers et al. 2008; Dawson et al. 1998), the contribution of working memory deficits to impaired imitation is unclear in this population and indeed, imitation tasks alone cannot discriminate between deficits in working memory, sensory information processing, and/or motor execution. In contrast, mirror drawing - when compared to drawing with direct view of the hand-can differentiate deficits in motor execution from deficits in visuospatial information processing underlying the transformation of goals into action. Although mirror-drawing has been studied in adults with autism including savants and non-savants (Hermelin et al. 1994), this task has not been studied in non-savant autistic children, who constitute the overwhelming majority of children diagnosed with autism, nor has it been used to compare the performance of individuals with autism to that of persons without autism. We hypothesize that children with autism differ from typically developing children in how they process sensory information to transform visuospatial goals into action. Moreover, if deficits in visuospatial information processing contribute to performance deficits in imitation, then mirror drawing performance should correlate with performance in imitation.

\section{Methods}

\section{Participants}

Twenty-seven children participated in this pilot study. Thirteen had diagnoses of autism spectrum disorder (ASD: autistic disorder, Asperger's disorder, or pervasive development disorder- not otherwise specified) [2 female; aged $14.5 \pm 1.6$ years, mean \pm standard deviation (here and elsewhere)] and 14 were typically developing (TYP) [3 female; aged $13.1 \pm 1.3$ years]. Children were recruited using online advertisements and by word-of-mouth within the Marquette University community. All children participated after informed assent and informed parental consent. All procedures were approved by Marquette University's institutional review board in compliance with the Declaration of Helsinki.

Social status was assessed with the Barratt Simplified Measure of Social Status (Barratt 2006). The ASD and TYP subject groups overlapped substantially in age and social status. Handedness was assessed with the Edinburgh Handedness Inventory (Oldfield 1971): right-handed ( $\mathrm{LI}>40)$, ambidextrous ( $-40 \leq \mathrm{LI} \leq 40$ ) and left-handed $(\mathrm{LI}<-40)$. Intelligence quotients (IQ) were measured with the Kaufman Brief Intelligence Test, second edition (KBIT2; Kaufman and Kaufman 2004). On average, the ASD and TYP groups had average intelligence quotients (IQ: 85 to 115$)$ with no difference between groups in verbal $(t(24)=-1.27 ; p=0.216)$, nonverbal $\left(t_{(25)}=-1.09\right.$; $p=0.284$ ) or total ( $t(24)=-1.24 ; p=0.227$ ) scores. (One TYP child was a non-native speaker of English, so his verbal/total KBIT2 scores were dropped). Autism or autism spectrum diagnoses were confirmed with the Autism Diagnostic Observation Schedule (ADOS; Lord, Rutter and Le Couteur 1994): a total score $\geq 7$ confirmed presence of an autism spectrum disorder $(n=4)$ and a score $\geq 10$ confirmed a diagnosis of autistic disorder $(n=9)$. Group statistics for age, sex, handedness, social status, KBIT2, ADOS, and medication are presented in Table $\underline{1}$.

Table 1. Participant characteristics

\begin{tabular}{|l|l|l|l|l|l|r|r|r|}
\hline Group & Participant & Age & Sex & Laterality & SS & KBIT2 & ADOS & Medication \\
\hline & & & & & & T (V, N) & T (C, S) & \\
\hline ASD & 1 & 12.6 & M & 90 & 48 & $87(84,93)$ & $10(4,6)$ & - \\
\hline
\end{tabular}




\begin{tabular}{|c|c|c|c|c|c|c|c|c|}
\hline & 2 & 13.0 & $M$ & -54 & 60 & $\begin{array}{l}127(129, \\
117)\end{array}$ & $8(1,7)$ & $A D, A H$ \\
\hline & 3 & 14.7 & $M$ & -100 & 59 & $104(87,119)$ & $14(5,9)$ & $S$ \\
\hline & 4 & 13.8 & $M$ & 100 & 38 & $81(89,78)$ & $\begin{array}{l}17(6, \\
11)\end{array}$ & $A D$ \\
\hline & 5 & 11.4 & $M$ & 100 & 21 & $107(117,95)$ & $\begin{array}{l}20(6, \\
14)\end{array}$ & - \\
\hline & 6 & 15.5 & $M$ & 30 & 34 & $\begin{array}{l}106(100, \\
110)\end{array}$ & $7(1,6)$ & $A D$ \\
\hline & 7 & 16.4 & $\mathrm{~F}$ & 0 & 45 & $101(92,109)$ & $\begin{array}{l}18(6, \\
12)\end{array}$ & - \\
\hline & 8 & 15.8 & $M$ & 89 & 42 & $102(106,96)$ & $9(3,6)$ & $A C, A P, A D$ \\
\hline & 9 & 15.9 & $M$ & -18 & 51 & $\begin{array}{l}110(116, \\
100)\end{array}$ & $10(3,7)$ & $S$ \\
\hline & 10 & 15.4 & $\mathrm{~F}$ & 100 & 64 & $114(97,126)$ & $11(3,8)$ & $A D$ \\
\hline & 11 & 16.1 & $M$ & 50 & 61 & $\begin{array}{l}101(102, \\
100)\end{array}$ & $12(4,8)$ & $S$ \\
\hline & 12 & 15.1 & $M$ & 50 & 22 & $99(112,85)$ & $11(3,8)$ & $A D$ \\
\hline & 13 & 12.7 & $M$ & 26 & 31 & $\begin{array}{l}115(117, \\
108)\end{array}$ & $7(2,5)$ & $A D$ \\
\hline & $M \pm S D$ & $14.5 \pm 1.6$ & - & $36 \pm 64$ & $44 \pm 14$ & $104 \pm 12$ & $12 \pm 4$ & - \\
\hline \multirow[t]{13}{*}{ TYP } & 1 & 13.8 & $M$ & 0 & 62 & $\begin{array}{l}120(120, \\
114)\end{array}$ & - & - \\
\hline & 2 & 11.0 & $\mathrm{~F}$ & 100 & 48 & $94(95,95)$ & - & - \\
\hline & 3 & 11.6 & $M$ & 90 & 62 & $*(*, 117)$ & - & - \\
\hline & 4 & 11.2 & $\mathrm{~F}$ & 88 & 66 & $\begin{array}{l}139 \text { (130, } \\
139)\end{array}$ & - & - \\
\hline & 5 & 14.5 & $M$ & 58 & 66 & $\begin{array}{l}116(122, \\
105)\end{array}$ & - & - \\
\hline & 6 & 13.8 & $M$ & 79 & 39 & $\begin{array}{l}109(101, \\
117)\end{array}$ & - & - \\
\hline & 7 & 14.7 & $M$ & 100 & 53 & $\begin{array}{l}104(101, \\
105)\end{array}$ & - & - \\
\hline & 8 & 15.3 & $\mathrm{~F}$ & 53 & 42 & $\begin{array}{l}106(108, \\
104)\end{array}$ & - & - \\
\hline & 9 & 12.7 & $M$ & 88 & 66 & $\begin{array}{l}117(121, \\
108)\end{array}$ & - & - \\
\hline & 10 & 14.4 & $M$ & 89 & 66 & $\begin{array}{l}109(111, \\
104)\end{array}$ & - & - \\
\hline & 11 & 12.5 & $M$ & 80 & 18 & $\begin{array}{l}125(124, \\
118)\end{array}$ & - & - \\
\hline & 12 & 12.9 & $M$ & 79 & 66 & $82(94,75)$ & - & - \\
\hline & 13 & 12.6 & $M$ & 100 & 46 & $\begin{array}{l}116(105, \\
122)\end{array}$ & - & - \\
\hline
\end{tabular}




\begin{tabular}{|c|c|c|c|c|c|c|c|}
\hline 14 & 12.8 & $\mathrm{M}$ & 100 & 32 & $\begin{array}{l}100(100, \\
100)\end{array}$ & - & - \\
\hline$M \pm S D$ & $13.1 \pm 1.3$ & - & $79 \pm 27$ & $52 \pm 15$ & $111 \pm 14$ & - & - \\
\hline
\end{tabular}

* Non-native English speaking participant

ASD autism spectrum disorder, TYP typically developing, SS social status, KBIT2 Kaufman Brief Intelligence Test, $2^{\text {nd }}$ Edition, $A D O S$ Autism Diagnostic Observation Schedule, $V$ verbal, $N$ nonverbal, $T$ total, $C$ communication, $S$ social, $M$ male, $F$ female, $A D$ anti-depressant, $A H$ anti-hypertensive, $S$ stimulant, $A C$ anti-convulsant, $A P$ antipsychotic, $\boldsymbol{M}$ mean, $S D$ standard deviation

\section{Experimental Procedures}

Each participant performed two experiments testing visually-guided, goal-directed motor performance in a single session lasting $\sim 30 \mathrm{~min}$. The experiments were designed to evaluate whether motor coordination deficits in autism arise from deficits in the formation of visuospatial representations of movement goals and/or in the utilization of these representations to guide ongoing movement.

\section{Experiment 1: Gesture Imitation}

Participants stood and watched a 12-min "interactive" video of a demonstrator who faced the camera and performed a set of 52 different discrete non-meaningful gesture sequences with the hands and arms. Gestures were presented one at a time in video form so that the demonstrated "target" gestures were the same for all participants. Target gestures were comprised of primitive elements including hand shape and sequences of movements with one or both arms. Hand shapes were derived from American Sign Language ("1", "5", "8", "S", "V" and "W") and movements involved one $(n=38)$ or both $(n=14)$ arms. Single-handed movements were made with the demonstrator's right hand. On average, each gesture's video clip lasted $5 \mathrm{~s}$. After each clip, the word 'Copy' appeared on a black background for $8 \mathrm{~s}$, instructing participants to imitate the gesture they had just observed. Thus, participants were required to commit the demonstrator's gesture to memory and then use that memory to guide production of their own hand and arm movements. No guidance was provided as to how participants should imitate the gestures, only that they should "do exactly what the demonstrator did" and thus the task was "goal-directed" because the participants' goal was to replicate the demonstrated movement. After imitating each gesture, participants were encouraged to resume a neutral position with arms at their sides. Each participant's movements were videotaped for later analysis of movement kinematics, as described below.

\section{Experiment 2: Shape Tracing With Direct and Mirrored Feedback}

Participants sat at a desk upon which six sheets of white paper were placed in succession. Each sheet was imprinted with a black outline of a $13 \times 13 \mathrm{~cm}^{2}$ geometric shape (circle, square or 5 -point star). The paper was centered along the subject's midline, with the bottom edge located 10 to $20 \mathrm{~cm}$ from his or her torso.

Participants were to trace the shape with a blue pen using their dominant hand while the arm rested in a lightweight, low-friction, chair-mounted arm support that eliminated tactile feedback between the arm and tabletop (MASF friction controlled mobile arm support, Jaeco Orthopedic, Inc.). Participants were instructed to start and stop their traces within a gray circle $(5 \mathrm{~mm}$ diameter) printed on the perimeter of the shape. Each shape was traced twice, once with direct visual feedback and once with mirror feedback. During direct visual feedback, participants traced with direct view of their hand. During mirror feedback, an opaque shield hovered above the pen, blocking direct view of the hand; participants viewed their hand in a vertical mirror situated opposite their dominant hand, causing leftward motions to appear as moving to the right, and vice versa. The order of shapes and viewing conditions was randomized across participants. If participants could not return to the starting position or if they did not comply with task instructions, they were allowed to repeat the drawing. Time to complete each drawing was recorded with a stopwatch. Data from three participants (ASD5, TYP2, and TYP11) were discarded due to inability or unwillingness to comply with task instructions. 


\section{Data Analysis}

For gesture imitation, the children's ability to spatially align their limb segments and the motions of these segments with remembered target gestures was analyzed. The demonstrator was viewed from the front (i.e. facing the camera) and thus, target gestures were observed within a spatial reference frame rotated 180 0 from the subject's body-image reference frame. As such, participants might adopt one of two viable imitation strategies. Participants could assume the demonstrator's perspective (an anatomical strategy requiring rotation of the target gestures into the subject's own body-image reference frame) or they could copy the movements as if in a mirror (a specular strategy requiring left-right reflection). Each child's videotaped trials were scored for quality in up to five performance categories (not all categories were appropriate for each demonstrated trial; see Table 2): (1) limb selection (anatomical, specular or unclear); (2) hand path/sequencing direction (accurate or inaccurate in accord with limb selection); (3) number of path strokes (accurate, greater than or less than demonstrated); (4) hand shape (accurate or inaccurate with respect to that demonstrated); and (5) hand orientation (accurate or inaccurate). We assumed that hand path/sequencing direction followed the strategy established by limb selection (Medendorp et al. 2005); therefore, path direction accuracy was defined with respect to the limb chosen by the subject for each individual trial. Three raters (first author and two raters who were blind to the study hypotheses and subject groups) evaluated each child's performance in each category. Inter-rater reliability was assessed with Fleiss' kappa and a majority vote of the three raters' scores produced a single score for each trial of each subject. For limb selection, we report the number of children in each group who chose the anatomical limb for the majority of trials. For the remaining four measures, we report the percentage of accurate trials out of the total number of trials per category. Performance measures were compared across groups using Analysis of Covariance (ANCOVA) with age, sex, and medication status (ON- or OFF-meds) as cofactors. Multiple correlation analysis was used to determine if total KBIT2 or ADOS scores correlated with any performance measure for either group.

Table 2. Categories of gesture imitation

\begin{tabular}{|c|c|c|c|c|c|c|c|}
\hline $\begin{array}{l}\text { Movement } \\
\text { description }\end{array}$ & & & $\begin{array}{l}\text { Scoring } \\
\text { categories }\end{array}$ & & & & \\
\hline & Movement type & $\begin{array}{l}\text { \# of } \\
\text { trials }\end{array}$ & $\begin{array}{l}\text { Limb } \\
\text { selection }\end{array}$ & $\begin{array}{l}\text { Path } \\
\text { direction }\end{array}$ & $\begin{array}{l}\text { Path } \\
\text { strokes }\end{array}$ & $\begin{array}{l}\text { Hand } \\
\text { shape }\end{array}$ & $\begin{array}{l}\text { Hand } \\
\text { orientation }\end{array}$ \\
\hline & & $(n)$ & (46) & (26) & $(32)$ & (52) & (52) \\
\hline \multirow[t]{8}{*}{ Unimanual } & $\begin{array}{l}\text { Raise the hand by } \\
\text { bending at the elbow }\end{array}$ & 12 & $x$ & & & $x$ & $x$ \\
\hline & Push the hand forward & 2 & $x$ & & & $x$ & $x$ \\
\hline & $\begin{array}{l}\text { Raise the hand, then } \\
\text { open/close the fingers }\end{array}$ & 4 & $x$ & & & $x$ & $x$ \\
\hline & $\begin{array}{l}\text { Abduct/adduct the } \\
\text { fingers }\end{array}$ & 2 & $x$ & & & $x$ & $x$ \\
\hline & $\begin{array}{l}\text { Move the hand about } \\
\text { an arc by rotating at } \\
\text { the elbow }\end{array}$ & 2 & $x$ & $x$ & $x$ & $x$ & $x$ \\
\hline & $\begin{array}{l}\text { Pronate/supinate the } \\
\text { forearm }\end{array}$ & 4 & $x$ & $x$ & $x$ & $x$ & $x$ \\
\hline & $\begin{array}{l}\text { Sequentially } \\
\text { flex/extend the fingers }\end{array}$ & 2 & $x$ & $\mathrm{x}$ & $\mathrm{x}$ & $\mathrm{x}$ & $x$ \\
\hline & Trace an invisible shape & 10 & $x$ & $x$ & $x$ & $x$ & $x$ \\
\hline Bimanual & $\begin{array}{l}\text { Alternate rotation of } \\
\text { the hands }\end{array}$ & 6 & & & $x$ & $x$ & $\mathrm{x}$ \\
\hline
\end{tabular}




\begin{tabular}{|l|l|l|l|l|l|l|}
\hline $\begin{array}{l}\text { Move right hand } \\
\text { up/down over the } \\
\text { stationary left hand }\end{array}$ & 4 & $X$ & $X$ & $X$ & $X$ & $X$ \\
\hline $\begin{array}{l}\text { Move left and right } \\
\text { hands in opposing } \\
\text { paths }\end{array}$ & 4 & $X$ & $X$ & $X$ & $X$ & $X$ \\
\hline
\end{tabular}

For shape tracing, the children's ability to minimize error between their drawing and the printed template was analyzed. Drawings were scanned to color JPEG files $(200 \times 200 \mathrm{dpi})$ and processed within the MATLAB computing environment (The Mathworks Inc., Natick, MA). Shape templates were separated from pen drawings with a color threshold. Shape templates were low-pass filtered and both images were converted to binary format ( imfilter and imcomplement functions). The lines of each image were thickened (imdilate function) using a $9 \times 9$ square structure element ( strel function). The centroid of the shape template was identified ( bwlabel and regionprops functions) and 360 equally spaced "sample points" were placed around the template's perimeter. The minimum distance between each sample point and any pixel in the pen drawing was computed and these distances were summed to yield a conservative measure of path error. Movement time and path error were averaged across shapes within participants for each viewing condition.

We analyzed performance separately for the direct viewing and mirror viewing conditions. During direct viewing, movement time and error from both subject groups were normally distributed. Therefore, performance measures were compared across groups using ANCOVA with age, sex, and medication as cofactors. During mirror viewing, data from the TYP group were normally distributed whereas data from the ASD group were nonGaussian with error concentrating on either side of mean \pm one standard deviation of the TYP distribution. Therefore, to assess whether ASD children differ from TYP children in how they transform visuospatial goals into action, we transformed path error and movement time data into $|z|$-scores (a Mahalanobis distance) on the TYP distribution for both subject groups:

$$
\begin{aligned}
& \left|z_{A S D}\right|=\left|\frac{x_{A S D}-\bar{x}_{T Y P}}{\sigma_{T Y P}}\right| \\
& \left|z_{T Y P}\right|=\left|\frac{x_{T Y P}-\bar{x}_{T Y P}}{\sigma_{T Y P}}\right| .
\end{aligned}
$$

In each case, $x$ corresponds to the independent variable of interest (path error or movement time), subscripts indicate the subject group, whereas $\bar{x}_{T Y P}$ and $\sigma_{T Y P}$ are the mean and standard deviation of the TYP distribution, respectively. Because Mahalanobis distance is strictly non-negative, the $|z|$-scores of movement time and path error were normalized prior to statistical testing using a Box-Cox transformation $[\lambda=0$; $B C=\ln (|z|)]$ (Box and Cox 1964). ANCOVA was used to compare group performance in the mirror viewing condition with age, sex, and medication as cofactors. Multiple correlation analysis determined whether total KBIT2 or ADOS scores were correlated with raw performance measures during direct viewing or with normalized $|z|$-score measures during mirror viewing. Linear regression evaluated the relationship between the unnormalized tracing error and duration data within each subject group. Finally, linear regression determined whether mirror drawing error could predict un-normalized performance in any of the imitation measures within each group. Statistical tests were performed using Minitab (Minitab, Inc., State College, PA) and SPSS (IBM, Armonk, NY) software. As this was a pilot study, we did not correct for multiple comparisons (i.e. effects were considered statistically significant at the $p=0.05$ threshold). 


\section{Results}

\section{Gesture Imitation}

Each child responded to each demonstrated gesture. The three raters achieved significant inter-rater reliability $(p<0.001)$ for each of the performance categories: limb selection [98\% agreement; $\mathrm{k}=0.97$ ], path direction [ $83 \%$ agreement; $\mathrm{k}=0.75$ ], number of path strokes [78 \% agreement; $\mathrm{k}=0.69$ ], hand shape [86 \% agreement; $\mathrm{K}=0.63$ ], hand orientation [81 \% agreement; $\mathrm{K}=0.54$ ]. Nine out of 13 children in the ASD group and 12 of 14 TYP children chose the anatomical limb in at least half of the movements. Compared to the TYP group, the ASD group had fewer accurate movements as quantified by: hand shape [TYP = $89 \pm 7 \%$, ASD = $83 \pm 8 \%$; ANCOVA: $\left.\mathrm{F}_{(1,22)}=10.55, p=0.004\right]$, hand orientation [TYP $=93 \pm 5 \%$, ASD $=77 \pm 16 \%$; ANCOVA: $\mathrm{F}_{(1,22)}=29.64, p<0.001$ ] and correct number of path strokes [TYP $=80 \pm 7 \%$, ASD $=61 \pm 21 \%$; ANCOVA: $F_{(1,22)}=17.05, p<0.001$ ] (Fig. 1). Children in the ASD group were as likely to produce more path strokes than needed as they were to produce fewer path strokes than needed [MORE $=22 \pm 23 \%$, FEWER $=17 \pm 12 \%, t(24)=0.77, p=0.449]$. Age was a significant cofactor for hand shape $\left(\mathrm{F}_{(1,22)}=5.18, p=0.033\right)$ and medication status was significant for hand orientation $\left(\mathrm{F}_{(1,22)}=9.63, p=0.005\right)$ and number of path strokes $\left(\mathrm{F}_{(1,22)}=5.14, p=0.033\right)$. Limb selection scores revealed that children did not frequently switch between anatomical and specular strategies when transforming visual goals into motor actions (Fig. 1a). There was no difference between groups in the choice of hand path direction as defined by the selected limb [TYP $=68 \pm 11 \%$, ASD $=65 \pm 17 \%$; ANCOVA: $F_{(1,22)}=0.09, p=0.766$ ]. Total KBIT2 scores were positively correlated with hand shape performance (Pearson's $r=0.516, p=0.046$ ) in the ASD group and positively correlated with hand orientation (Pearson's $r=0.742, p=0.004$ ) in the TYP group.
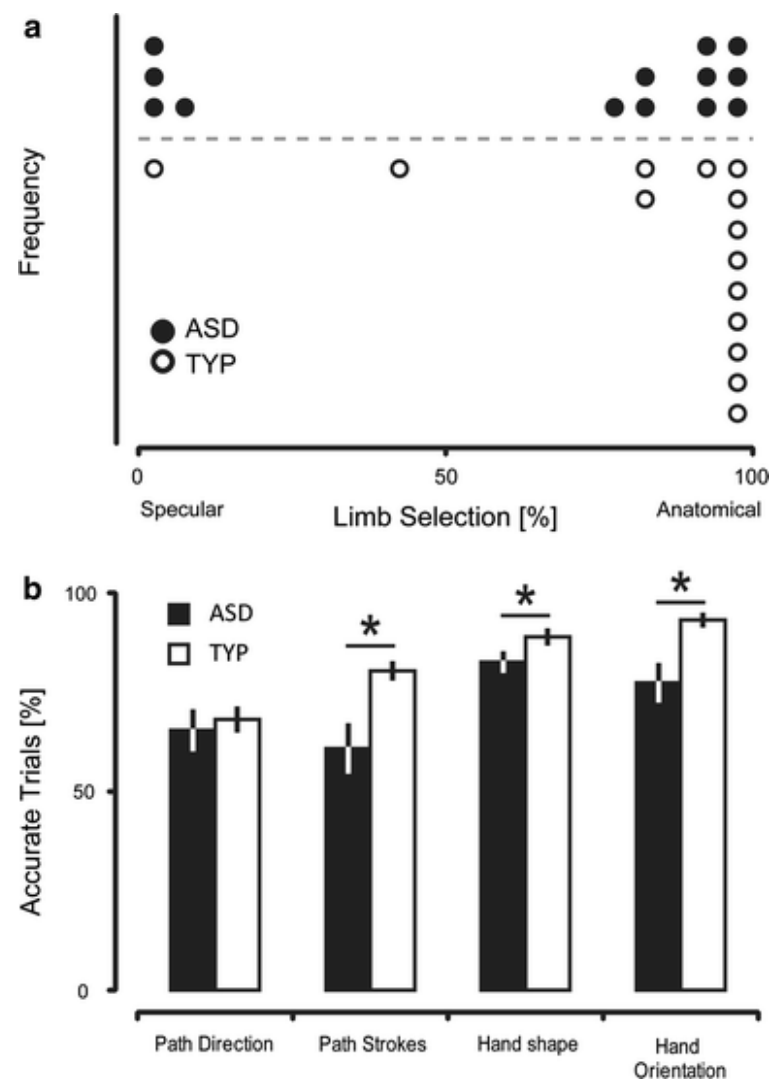

Fig. 1

Gesture imitation. a Histograms of percent limb selection for ASD participants (filled) and TYP participants (open) and $\mathbf{b}$ mean percentage of accurate movements for children with autism [ASD, filled] and typically developing children [TYP, open] during imitation for each scoring category. Dotted lines indicate separation between groups here and elsewhere. Vertical error bars: \pm 1 SEM. ${ }^{*} p<0.005$ 
Five children with ASD but none of the TYP children exhibited perseveration in at least one of the movements (i.e. they moved their hand repeatedly along an erratic path). Even though all the demonstration gestures incorporated simultaneous hand shape formation and limb movement, many children in both groups performed gestures using separate postural adjustment and movement phases. That is, they copied the demonstrator's hand shape prior to limb movement while directly looking at their own hand, then they completed the arm movements in a second, distinct phase. For the unimanual gestures, one child in the ASD group repeatedly copied the demonstrator's hand shape with his left hand while watching the demonstration, then made the movement during the 'Copy' screen using his right hand and arm.

\section{Shape Tracing}

To address the question of whether the ASD group differed from the TYP group in their ability to execute shapetracing tasks, we assessed group differences in path error (TYP $=985 \pm 558 \mathrm{~mm}$, ASD $=819 \pm 547 \mathrm{~mm}$ ) and movement time (TYP $=16.1 \pm 8.9 \mathrm{~s}, \mathrm{ASD}=23.1 \pm 9.9 \mathrm{~s}$ ) in the direct viewing condition. We found that when the hand was viewed directly, performance of shape tracing was similar across groups (Fig. 2) for both path error [ANCOVA: $\mathrm{F}_{(1,19)}=0.97, p=0.337$ ] and movement time [ANCOVA: $\mathrm{F}_{(1,19)}=2.26, p=0.150$ ]. No cofactor exerted significant influence over movement time or error.

$$
\text { a }
$$
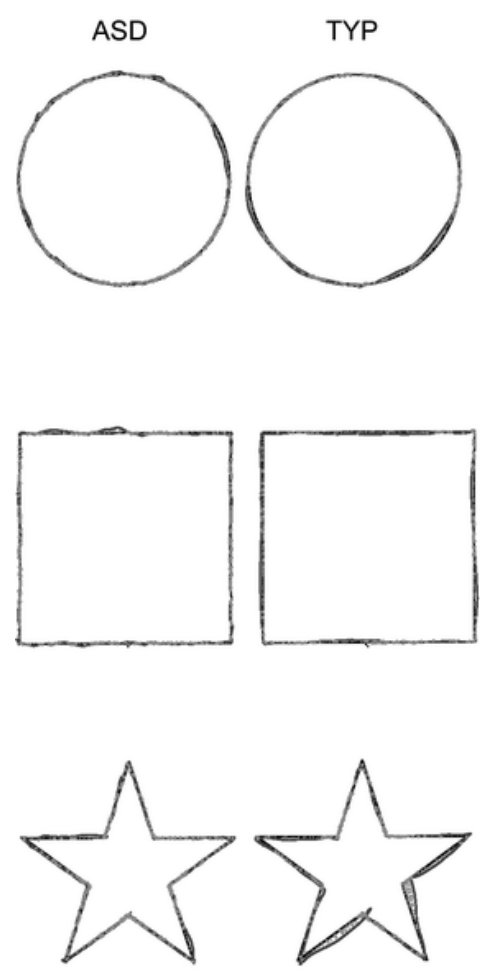
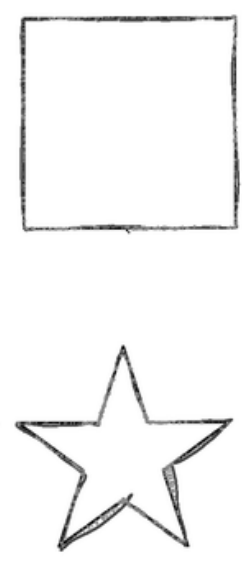

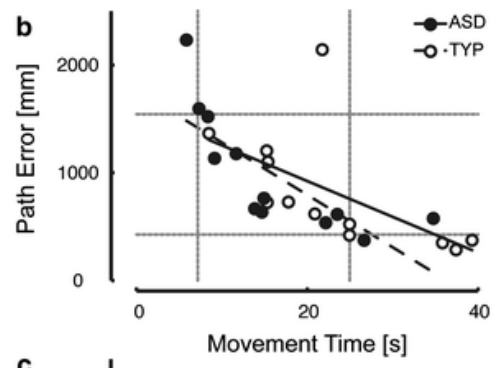

c
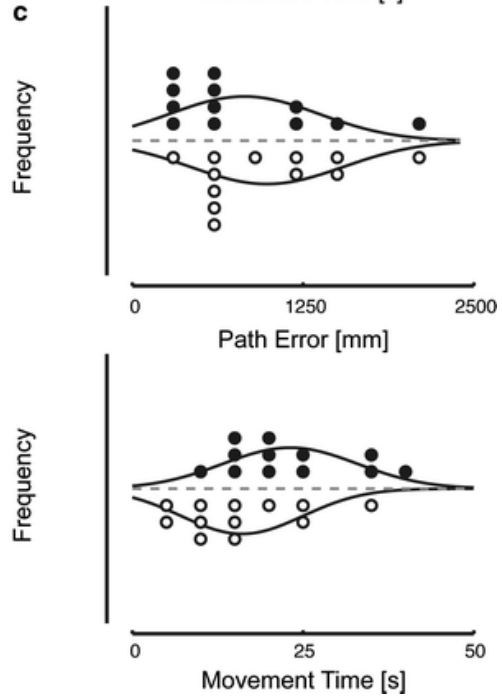

\section{Fig. 2}

Shape tracing (direct view). a Drawings [thick, gray lines] and shape templates [thick, black lines] from a representative child with autism (ASD1) and a typically developing child (TYP1). Path error was computed as the sum of deviations [thin, gray lines] from 360 equally-spaced sample points along the template path. $\mathbf{b}$ Linear regressions of path error as a function of movement time for ASD (filled, solid line) and TYP (open, dashed line) groups. Grey dotted lines represent $\bar{X}^{-}$TYP $\pm \sigma$ TYP. $\mathrm{c}$ Histograms of path error and movement time

To determine whether the ASD group deviated from the TYP group in their capacity for visuospatial information processing during shape-tracing, we assessed group differences in path error and movement time in the mirror 
viewing condition. Here, hand path errors and movement times were generally greater than those obtained during direct viewing (Fig. $\underline{3}$ ). But whereas path errors were normally distributed in the TYP group (3831 $\pm 2025 \mathrm{~mm}$ ), the distribution of errors deviated from normality in the ASD group. Only 5 out of 12 ASD participants had path errors within \pm 1 standard deviation (SD) of the TYP group: 5 were above and 2 were below that range. A similar group-wise difference in the distributions of movement times was also observed. Altogether, 8 of 13 ASD participants had mirror drawing errors and/or movement times outside the range established by the TYP group mean \pm 1 SD (Fig. $\underline{3} b$, top).
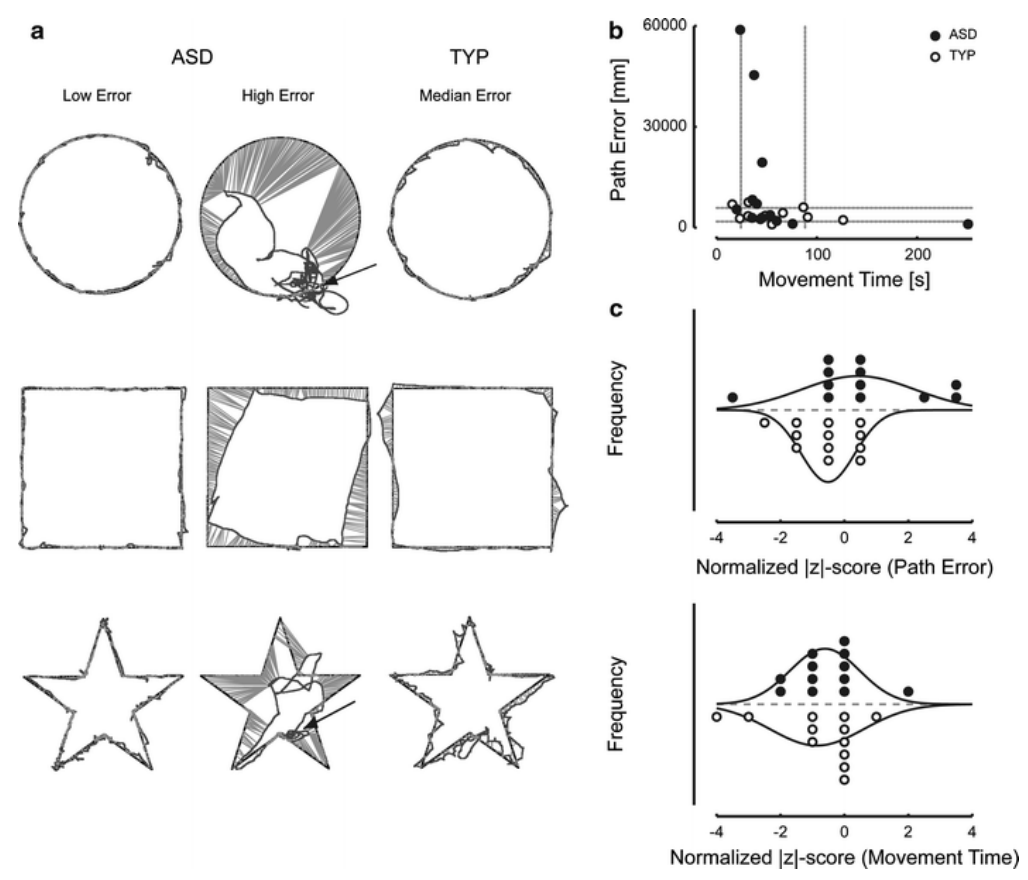

\section{Fig. 3}

Shape tracing (mirror view). a Drawings, shape templates and path deviation measures from a representative child with autism who had low error [left; ASD6], a child with autism who had high error [middle; ASD1] and a typically developing child with a median level of error [right; TYP1]. Path errors were computed as described in Fig. 2. Regions of perseveration are highlighted with arrows. b Path error as a function of movement time for ASD and TYP groups. Grey dotted lines represent $X^{-}$TYP $\pm \sigma T Y P, \mathbf{c}$ Histograms of Box-Cox normalized $|z|$-scores related to path error and movement time

To quantify how much the ASD group deviated from average TYP performance, we converted movement time and path error to $|z|$-scores in each group and then used a standard Box-Cox transformation $[\ln (|z|)]$ to normalize each distribution (see Methods). ANCOVA found that ASD participants generated path errors that were outside the distribution of the TYP group during mirror drawing [Box-Cox transformed $|z|$-scores: TYP $=-0.51 \pm 0.84$, ASD $=0.43 \pm 1.77$; ANCOVA: $\left.F_{(1,19)}=4.59, p=0.045\right]$. This outcome lends preliminary support to the hypothesis that children with ASD differ from TYP children in how they process sensory information to transform visuospatial goals into action. A separate ANCOVA found no effect of group on movement time. Age, sex, and medication status were not significant cofactors for any $|z|$-score performance measure.

Path error was correlated with total KBIT2 scores in the ASD group during direct viewing (Pearson's $r=-0.603$, $p=0.038$ ) but there was no such correlation between path error and total ADOS scores nor was there a relationship between path error and KBIT2 in the TYP group. Movement time was uncorrelated with total KBIT2 scores in both groups and movement time was uncorrelated with total ADOS scores in the ASD group. Path error $|z|$-scores were correlated with total KBIT2 scores in the TYP group (Pearson's $r=-0.761, p=0.007$ ) but neither $\mathrm{KBIT2}$ nor ADOS scores were correlated with path error $|z|$-scores in the ASD group during mirror viewing. 
Movement time $|z|$-scores were not correlated with total KBIT2 scores in either group and were uncorrelated with ADOS scores in the ASD group. We found an inverse relationship between error and movement time in both groups during direct viewing [TYP: $\mathrm{F}_{(1,11)}=16.44, t_{(11)}=-4.05, p=0.002 ;$ ASD: $\mathrm{F}_{(1,11)}=6.13, t_{(11)}=-2.48$, $p=0.031$, but not during mirror viewing.

One child with autism (ASD1) exhibited 'perseverative' movements in which the pen was moved repeatedly in quasi-random motions (Fig. $\underline{3}$, arrows). Another child with autism (ASD3) incrementally pivoted the pen and hand while correcting for errors (a motion resembling that of an inchworm); this data was discarded and he repeated the task (without pivoting the hand) on a second day's visit to the lab. In addition, six children with ASD and four children in the TYP group periodically 'jittered' the pen during mirror drawing. The three ASD children who had been using stimulants achieved errors within one SD of the mean of the TYP group.

We tested the hypothesis that deficits in visuospatial information processing can predict imitation performance deficits by evaluating the relationship between mirror drawing error and each imitation sub-score using linear regression for each subject group. Mirror drawing error was correlated with hand orientation during imitation in the TYP group $\left(R^{2}=72 \%, t=5.13, p<0.001 ;\right.$ Fig. $\left.4 a\right)$. A similar relationship was evident for the ASD participants $\left(R^{2}=48 \%, t=2.86, p=0.019\right.$; Fig. 4a) if we exclude the only ASD subject (ASD8) taking anti-psychotic and anticonvulsant medications at the time of the study and whose performance was inconsistent with the trend between mirror drawing error and hand orientation established by the TYP group. Similarly, we find that mirror drawing error was correlated with deficits in hand shape formation in the ASD group $\left(R^{2}=67 \%, t=4.31\right.$, $p=0.002$; Fig. 4 b). Thus, children who produced large mirror drawing errors also made more hand orientation errors in the imitation task in both groups and children with ASD who made large mirror drawing errors also made large hand shape errors during imitation. No other imitation scores were correlated with mirror drawing error.
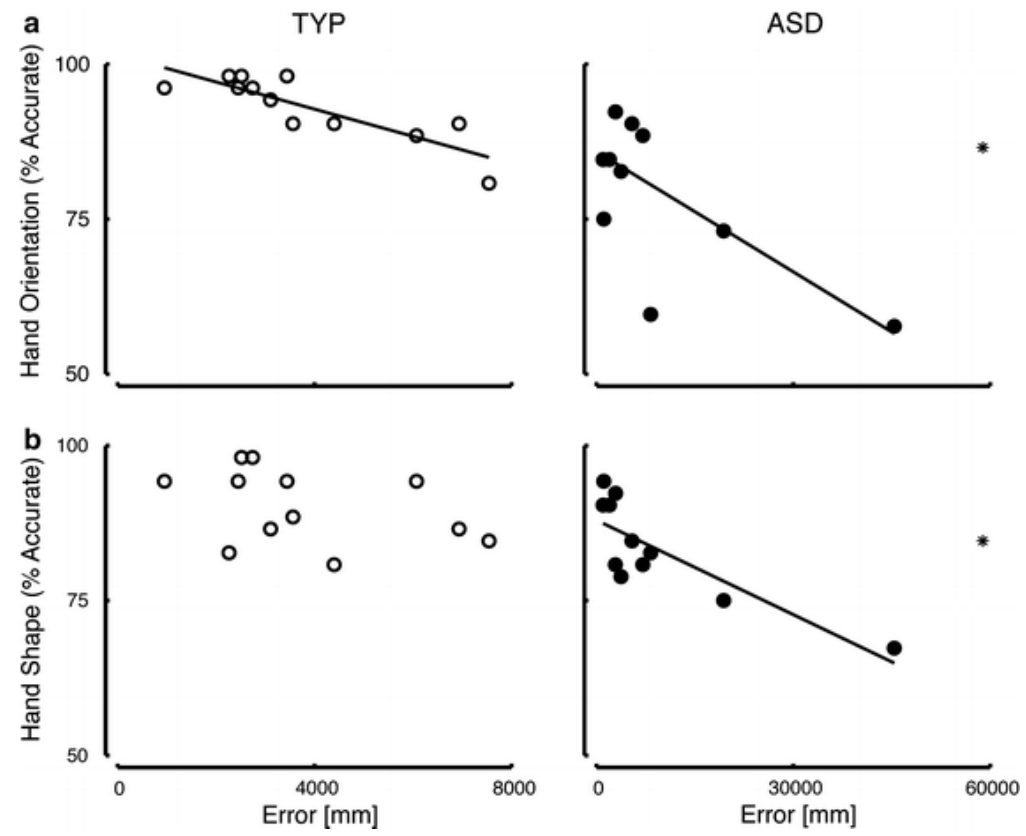

Fig. 4

Mirror drawing errors correlate with gesture imitation performance. a Hand orientation was correlated with mirror drawing error in the TYP group (left, open) and the ASD group (right, filled). One child who took three medications (including an anti-psychotic and an anti-convulsant) on the day of the study (ASD8, *) did not perform in a manner consistent with the trend between mirror drawing error and hand orientation established by the TYP group and was dropped from the regression. $\mathbf{b}$ Hand shape was also correlated with mirror drawing error in the ASD group (right, filled) 


\section{Discussion}

Gesture imitation and mirror drawing revealed abnormalities in the way children with ASD transform visuallyspecified goals into motor actions. During imitation, children with ASD were less accurate than TYP children in replicating hand shape, hand orientation, and number of constituent limb movements. These children likely did not suffer generally from problems with motor execution because they traced shapes with speed and accuracy comparable to that of TYP children when viewing the hand directly. However, when viewing the hand in a mirror, the magnitudes of errors in the ASD group were largely outside the distribution of errors made by the TYP group. Some ASD participants performed better than TYP children whereas others performed much worse. Moreover, mirror drawing error was correlated with hand orientation and hand shape deficits in imitation, suggesting that the ability to adapt to a new sensorimotor transformation was abnormal in children with ASD in both tasks. These results suggest that abnormalities in visuospatial information processing may contribute to functional motor coordination deficits in ASD.

Imitation is an important skill for child development (Rogers et al. 2003) and ability to perform imitation tasks is correlated with social responsivity (Rogers et al. 2003) and expressive language skills (Stone, Ousley and Littleford 1997) in children with autism. Imitation deficits distinguish children with autism from those with other developmental disorders (Rogers et al. 2003; Stone, Ousley and Littleford 1997). Imitation, as studied here, is a complex behavior that requires directed attention and the ability to identify, remember, and execute movements toward visuospatial goals. The deficits we observed during imitation were not likely due to an inability to attend to the instructed task, because each child attempted to imitate every instructed gesture during the cued "copy" interval. During hand shape formation and orienting, the children had to transform a two-dimensional representation of the demonstrator's hand into the three-dimensional configuration of their own hand, and ASD children made more errors than TYP children. These aspects of task performance require (but cannot differentiate between) the identification, memorization, and recall of visuospatial goals, as well as execution of actions appropriate to acquire those goals. Reproducing the correct number of hand path strokes during imitation also requires the encoding, recall, and execution of a sequence of movements between a set of desired spatial goals; ASD children underperformed the TYP cohort in this respect as well. In contrast, limb selection was a cognitive choice with no clear "right" or "wrong" classification. Most children (ASD and TYP) chose the anatomical limb to perform the instructed gesture in most trials, and given that choice, ASD and TYP children were equally consistent in directing limb movements commensurate with their selected strategy. In contrast, Hamilton, et al. (2007) found that young children (ASD and TYP) were more likely to use the specular limb in a task that followed an earlier experiment in which mirror imitation was required. Therefore, limb selection may be influenced by prior instructions and practice.

Imitation is also impaired in ASD when visual feedback is unavailable (oral-facial imitation, Rogers et al. 2003). A potential limitation of our imitation task is that we did not evaluate performance without ongoing visual feedback of limb movement and hand shape formation. As such, we cannot determine conclusively whether the imitation deficits we observed were due to deficits in the ability to adapt the visuospatial sensorimotor map needed to transform intended movements into motor commands or whether they were due to deficits in the moment-by-moment visual feedback guidance of an ongoing movement, which relies on that transformation. Future studies should include a condition in which ongoing visual feedback is unavailable.

Mirror drawing is neither typically encountered in daily life nor ecologically relevant, but it can differentiate deficits of attention and motor execution from those of visuospatial representation, particularly when contrasted with shape tracing performance during direct viewing. Group differences in error compensation during mirror viewing were not likely due to general deficits in either attention and/or the ongoing visual feedback guidance of movement (i.e. motor execution) because we found no group differences in shape tracing with direct view of limb movement. However, the pattern of mirror drawing errors we observed suggests differences in how the TYP and ASD groups form the sensorimotor maps needed to transform visuospatial goals into motor commands. Participants in both groups periodically "jittered" the pen, presumably in an attempt to 
identify the novel visuospatial transformation imposed by the mirror. Jittering the pen effectively injects noise into the limb/pen system (Miall, Weir and Stein 1993) and by monitoring the (visual) consequence of that action, the participant can identify motor commands that achieve the goal under the new visuospatial transformation [i.e. by learning an inverse of the mapping from motor commands onto their kinematic consequences (cf. Liu et al. 2011)].

Viewing the hand in a mirror establishes unusual conflict between how vision and proprioception (muscle-based limb position sense) report the direction of hand movement in response to descending motor commands. Thus another possible strategy to compensate for sensorimotor transformation is to modify the relative contributions of vision and proprioception for motor command updating. During mirror drawing, if proprioception is blocked transiently (transcranial magnetic stimulation: Balslev et al. 2004) or chronically (deafferentation: Lajoie et al. 1992 ) adults perform with less error than when proprioception is available. Previous research (Hermelin and O'Connor 1970) has shown that sensory dominance and integration are abnormal in children with autism. Thus, a plausible explanation for differences in mirror drawing seen here is that some children with ASD favored visual cues and were thus better able to reduce errors (Fig. $3 a$, 'Low Error') while others ignored visual errors in favor of proprioceptive cues, thereby producing large errors during mirror drawing (Fig. $\underline{3} a$, 'High Error'). Future studies of visuospatial learning in ASD should include assessment of visuo-proprioceptive bias, which might help explain the elevated motor performance variability observed in this participant group.

Importantly, abnormalities in mirror tracing in ASD predicted deficits of hand orientation and hand shape during imitation, raising the possibility of a common etiology of errors in the two tasks. Imitation and mirror drawing engage the frontal lobes [Brodmann area 45 (Iacoboni 2005) and dorsolateral prefrontal cortex (Imamura et al. 1996)], which are important for executive function and which exhibit anatomical and functional abnormalities in children with ASD (Courchesne and Pierce 2005). It is likely that physiological abnormalities of the frontal lobes contribute importantly to visuospatial performance deficits in ASD. Rumiati et al. (2005) propose that imitation, specifically, involves distinct neural processes involved in the recall and execution of over-learned "meaningful" actions and the transformation of novel but "meaningless" visuospatial targets into actions. Our study only involved reproduction of "meaningless" actions and so we feel our findings can only speak to possible impairment of the dorsal processing stream identified by Rumiati et al. (2005), which includes brain regions thought to be involved in the representation of visual goals in proprioceptive coordinate frames (i.e. parietal association areas; cf. Grefkes et al. 2004) as well as areas more directly involved in goal-directed action (ventral premotor and primary motor cortices).

In summary, the results of this pilot study support the hypothesis that impaired visuospatial information processing is a cause of functional coordination deficits in children with ASD. Future studies should be conducted to test these preliminary findings in a larger cohort of ASD participants using experimental approaches specifically designed to quantify the ability to process visuospatial information during goal-directed movement while controlling for abnormalities (and/or bias) in multimodal sensory integration.

\section{Acknowledgments}

We thank the participants and their families for their dedication to our research efforts. We are grateful to Diksha Gandhi and Natdhaphol Kulvadhanaphan for scoring the gesture imitation videos. This work was supported by a grant from the National Science Foundation BES0238442 and by the Way-Klingler Family Foundation. Portions of this work have been presented previously in abstract form at the Society for Neuroscience conference (Salowitz et al. 2011).

\section{References}

1. American Psychiatric Association. (1994). Diagnostic and statistical manual of mental disorders (4th ed.). Washington, DC: American Psychiatric Association. 
2. Balslev, D., Christensen, L. O. D., Lee, J., Law, I., Paulson, O. B., \& Miall, R. C. (2004). Enhanced accuracy in novel mirror drawing after repetitive transcranial magnetic stimulation-induced proprioceptive deafferentation. Journal of Neuroscience, 24(43), 9698-9702.

3. Barratt, W. (2006). The Barratt Simplified Measure of Social Status (BSMSS) measuring SES. Unpublished Manuscript. Indiana State University, http://wbarratt.indstate.edu/socialclass/Barratt Simplifed Measure of Social Status.pdf.

4. Bernabei, P., Fenton, G., Fabrizi, A., Camaioni, L., \& Perucchini, P. (2003). Profiles of sensorimotor development in children with autism and with developmental delay. Perceptual and Motor Skills, 96, 11071116.

5. Box, G. E. P., \& Cox, D. R. (1964). An analysis of transformations. Journal of the Royal Statistical Society: Series B, 26(2), 211-252.

6. Courchesne, E., \& Pierce, K. (2005). Why the frontal cortex in autism might be talking only to itself: Local over-connectivity but long-distance disconnection. Current Opinion in Neurobiology, 15, 225-230.

7. Dawson, G., Meltzoff, A. N., Osterling, J., \& Rinaldi, J. (1998). Neuropsychological correlates of early symptoms of autism. Child Development, 69(5), 1276-1285.

8. Ghaziuddin, M., \& Butler, E. (1998). Clumsiness in autism and Asperger syndrome: A further report. Journal of Intellectual Disability Research, 42(1), 43-48.

9. Ghaziuddin, M., Butler, E., Tsai, L., \& Ghaziuddin, N. (1994). Is clumsiness a marker for Asperger syndrome? Journal of Intellectual Disability Research, 38, 519-527.

10. Gidley Larson, J. C., Bastian, A. J., Donchin, O., Shadmehr, R., \& Mostofsky, S. H. (2008). Acquisition of internal models of motor tasks in children with autism. Brain, 131, 2894-2903.

11. Glazebrook, C. M., Elliott, D., \& Szatmari, P. (2008). How do individuals with autism plan their movements? Journal of Autism and Developmental Disorders, 38, 114-126.

12. Grefkes, C., Ritzl, A., Zilles, K., \& Fink, G. R. (2004). Human medial intraparietal cortex subserves visuomotor coordinate transformation. Neurolmage, 23, 1494-1506. Hamilton, A. F., Brindley, R. M., \& Frith, U. (2007). Imitation and action understanding in autistic spectrum disorders: How valid is the hypothesis of a deficit in the mirror neuron system? Neuropsychologia, 45(8), 1859-1868.

13. Haswell, C. C., Izawa, J., Dowell, L. R., Mostofsky, S. H., \& Shadmehr, R. (2009). Representation of internal models of action in the autistic brain. Nature Neuroscience, 12(8), 970-972.

14. Hermelin, B., \& O'Connor, N. (1970). Psychological experiments with autistic children. Oxford: Permagon Press.

15. Hermelin, B., Pring, L., \& Heavey, L. (1994). Visual and motor functions in graphically gifted savants. Psychological Medicine, 24, 673-680.

16. Hill, E. L. (2004). Executive dysfunction in autism. Trends in Cognitive Sciences, 8(1), 26-32.

17. Iacoboni, M. (2005). Neural mechanisms of imitation. Current Opinion in Neurobiology, 15, 632-637.

18. Imamura, K., Onoe, H., Watanabe, Y., Andersson, J., Hetta, J., Schneider, H., et al. (1996). Regional activation of human cerebral cortex upon an adaptation in mirror drawing. Neuroscience Letters, 209, 185-188.

19. Kaufman, A. S., \& Kaufman, N. L. (2004). Kaufman brief intelligence test (2nd ed.). Minneapolis, MN: NCS Pearson, Inc.

20. Lajoie, Y., Paillard, J., Teasdale, N., Bard, C., Fleury, M., Forget, R., et al. (1992). Mirror drawing in a deafferented patient and normal subjects: Visuoproprioceptive conflict. Neurology, 42, 1104-1106.

21. Lane, A., Young, R., Baker, A., \& Angley, M. (2010). Sensory processing subtypes in autism: Association with adaptive behavior. Journal of Autism and Developmental Disorders, 40, 112-122.

22. Leighton, J., Bird, G., Charman, T., \& Heyes, C. (2008). Weak imitative performance is not due to a functional 'mirroring' deficit in adults with Autism Spectrum Disorders. Neuropsychologia, 46, 1041-1049.

23. Liu, X., Mosier, K. M., Mussa-Ivaldi, F. A., Casadio, M., \& Scheidt, R. A. (2011). Reorganization of finger coordination patterns during adaptation to rotation and scaling of a newly-learned sensorimotor transformation. Journal of Neurophysiology, 105, 454-473.

24. Lord, C., Rutter, M., \& Le Couteur, A. (1994). Autism diagnostic observation schedule-WPS edition. Los Angeles, CA: Western Psychological Services. 
25. Medendorp, W. P., Goltz, H. C., Crawford, J. D., \& Vilis, T. (2005). Integration of target and effector information in human posterior parietal cortex for the planning of action. Journal of Neurophysiology, 93, 954-962.

26. Miall, R., Weir, D., \& Stein, J. (1993). Intermittency in Human manual tracking. Journal of Motor Behavior, 25, 53-63.

27. Minshew, N. J., Sung, K., Jones, B. L., \& Furman, J. M. (2004). Underdevelopment of the postural control system in autism. Neurology, 63, 2056-2061.

28. Molloy, C. A., Dietrich, K. N., \& Bhattacharya, A. (2003). Postural stability in children with autism spectrum disorder. Journal of Autism and Developmental Disorders, 33(6), 643-652.

29. Mostofsky, S. H., Bunoski, R., Morton, S. M., Goldberg, M. C., \& Bastian, A. J. (2004). Children with autism adapt normally during a catching task requiring the cerebellum. Neurocase, 10(1), 60-64.

30. O'Neill, M., \& Jones, R. (1997). Sensory-perceptual abnormalities in autism: A case for more research? Journal of Autism and Developmental Disorders, 27, 283-293.

31. Ohta, M. (1987). Cognitive disorders of infantile autism: A study employing the WISC, spatial relationship conceptualization, and gesture imitations. Journal of Autism and Developmental Disorders, 17(1), 45-62.

32. Oldfield, R. (1971). The assessment and analysis of handedness: The Edinburgh inventory. Neuropsychologia, 9, 97-113.Rinehart, N. J., Bellgrove, M. A., Tonge, B. J., Brereton, A. V., Howells-Rankin, D., \& Bradshaw, J. L. (2006). An examination of movement kinematics in young people with high-functioning autism and Asperger's disorder: Further evidence for a motor planning deficit. Journal of Autism and Developmental Disorders, 36, 757-767.

33. Rinehart, N. J., Bradshaw, J. L., Brereton, A. V., \& Tonge, B. J. (2001). Movement preparation in highfunctioning autism and Asperger disorder: A serial choice reaction time task involving motor reprogramming. Journal of Autism and Developmental Disorders, 31(1), 79-88.

34. Rogers, S. J., Hepburn, S. L., Stackhouse, T., \& Wehner, E. (2003). Imitation performance in toddlers with autism and those with other developmental disorders. Journal of Child Psychology and Psychiatry, 44(5), 763-781.

35. Rogers, S. J., Young, G. S., Cook, I., Giolzetti, A., \& Ozonoff, S. (2008). Deferred and immediate imitation in regressive and early onset autism. Journal of Child Psychology and Psychiatry, 49(4), 449-457.

36. Rumiati, R. I., Weiss, P. H., Tessari, A., Assmus, A., Zilles, K., Herzog, H., et al. (2005). Common and differential neural mechanisms supporting imitation of meaningful and meaningless actions. Journal of Cognitive Neuroscience, 17(9), 1420-1431.Salowitz, N. M. G., Vaughan Van Hecke, A., \& Scheidt, R. A. (2011). Mirror drawing in an autistic child. In Program No. 696.04. Neuroscience Meeting Planner. Washington, DC: Society for Neuroscience (Online).

37. Schmitz, C., Martineau, J., Barthélémy, C., \& Assaiante, C. (2003). Motor control and children with autism: Deficit of anticipatory function? Neuroscience Letters, 348(1), 17-20.

38. Stone, W. L., Ousley, O. Y., \& Littleford, C. D. (1997). Motor imitation in young children with autism: What's the object? Journal of Abnormal Child Psychology, 25(6), 475-785.

39. Vivanti, G., Nadig, A., Ozonoff, S., \& Rogers, S. J. (2008). What do children with autism attend to during imitation tasks? Journal of Experimental Child Psychology, 101, 186-205.

40. Wiggins, L., Robins, D., Bakeman, R., \& Adamson, L. (2009). Brief report: Sensory abnormalities as distinguishing symptoms of autism spectrum disorders in young children. Journal of Autism and Developmental Disorders, 39, 1087-1091.

41. Williams, J. H. G., Whiten, A., Suddendorf, T., \& Perrett, D. I. (2001). Imitation, mirror neurons and autism. Neuroscience and Biobehavioral Reviews, 25, 287-295. 